Research, Society and Development, v. 9, n. 8, e637984240, 2020

(CC BY 4.0) | ISSN 2525-3409 | DOI: http://dx.doi.org/10.33448/rsd-v9i8.6240

\title{
Mapeamento das relações entre estresse e desempenho acadêmico na educação superior
}

Relationship mapping between stress and academic performance in higher education

Mapeo de relaciones entre el estrés y el rendimiento académico en educación universitaria

Recebido: 02/07/2020 | Revisado: 05/07/2020 | Aceito: 07/07/2020 | Publicado: 22/07/2020

Charliany Silva Araújo

ORCID: http://orcid.org/0000-0003-1499-9671

Instituto Federal de Educação, Ciência e Tecnologia do Rio Grande do Norte, Brasil

E-mail: charlianysilvaa@gmail.com

Leonor de Araújo Bezerra Oliveira

ORCID: http://orcid.org/0000-0002-1374-4215

Instituto Federal de Educação, Ciência e Tecnologia do Rio Grande do Norte, Brasil

E-mail: leonor.oliveira@ifrn.edu.br

Samuel de Carvalho Lima

ORCID: http://orcid.org/0000-0002-7145-3686

Instituto Federal de Educação, Ciência e Tecnologia do Rio Grande do Norte, Brasil

E-mail: samuel.lima@ifrn.edu.br

\section{Resumo}

O presente artigo objetiva mapear as relações entre o estresse e o desempenho acadêmico de alunos da educação superior. A investigação exploratória, de natureza qualitativa, fundamentou-se nas discussões sobre o impacto do estresse no desempenho de funções cognitivas. O contexto da pesquisa foi o curso superior de Tecnologia em Gestão Ambiental do Instituto Federal de Educação, Ciência e Tecnologia do Rio Grande do Norte, campus Mossoró. Utilizou-se de questionário para a construção dos dados. Foram participantes da pesquisa alunos do $1^{\circ}$ e do $5^{\circ}$ semestre do curso para identificar suas percepções sobre o estresse acadêmico. Simultaneamente, essas percepções foram relacionadas ao seu desempenho. A análise dos dados revelou que o estresse está mais relacionado à pressão por notas satisfatórias e é mais evidente entre os alunos do $5^{\circ}$ semestre. Conclui-se que o estresse é percebido ao longo da vida acadêmica e influencia o desempenho acadêmico em semestres mais avançados. Recomendam-se sugestões de atitudes ou atividades que possam minimizar o estresse percebido pelos alunos. 
Palavras-chave: Estresse; Desempenho acadêmico; Educação superior; Ensino.

\begin{abstract}
This paper aims to map the relationship between stress and academic performance of students in higher education. The exploratory investigation of qualitative nature was based on discussions about the impact of stress on the performance of cognitive functions. The research context was the higher course in Technology in Environmental Management at the Federal Institute of Education, Science and Technology of Rio Grande do Norte, campus Mossoró. Semi-structured interviews were used to build data. Students from the 1 st and the 5th semester of the course were interviewed to identify their perceptions about academic stress. A questionnaire was used to construct the data. Students from the 1st to the 5th semester of the course participated in the research to identify their perceptions about academic stress. Simultaneously, these perceptions were related to their performance. Data analysis revealed that stress is more related to pressure for satisfactory grades and is more evident among students in the 5th semester. It is concluded that stress is perceived throughout academic life and influences academic performance in more advanced semesters. Suggestions of attitudes or activities that can minimize the stress perceived by the students are recommended.
\end{abstract}

Keywords: Stress; Academic performance; Higher education; Teaching.

\title{
Resumen
}

Este artículo tiene como objetivo mapear la relación entre el estrés y el rendimiento académico de los estudiantes de educación superior. La investigación exploratoria, de naturaleza cualitativa, se basó en discusiones sobre el impacto del estrés en el desempeño de las funciones cognitivas. El contexto de investigación fue el curso superior de Tecnología en Gestión Ambiental en el Instituto Federal de Educación, Ciencia y Tecnología de Rio Grande do Norte, campus Mossoró. Se utilizaron entrevistas semiestructuradas para construir datos. Los estudiantes del primer y quinto semestre del curso fueron entrevistados para identificar sus percepciones sobre el estrés académico. Se utilizó un cuestionario para construir los datos. Los estudiantes del $1^{\circ}$ al $5^{\circ}$ semestre del curso participaron en la investigación para identificar sus percepciones sobre el estrés académico. Simultáneamente, estas percepciones estaban relacionadas con su desempeño. El análisis de datos reveló que el estrés está más relacionado con la presión para obtener calificaciones satisfactorias y es más evidente entre los estudiantes en el quinto semestre. Se concluye que el estrés se percibe a lo largo de la vida académica e influye en el rendimiento académico en semestres más avanzados. Se recomiendan 
sugerencias de actitudes o actividades que puedan minimizar el estrés percibido por los estudiantes.

Palabras clave: Estrés; Desempeño académico; Educación universitaria; Enseñanza.

\section{Introdução}

Estudos que problematizam o estresse no contexto escolar e acadêmico não são recentes e ainda se constituem pauta na agenda contemporânea para a elaboração de programas para sua prevenção. Monteiro, Freitas \& Ribeiro (2007) salientam que as situações de estresse podem gerar problemas de ordem de aprendizagem, raciocínio, memória e impactar outras funções cognitivas. Os autores discutem que as crises de estresse são responsáveis pela produção e liberação de hormônios específicos que são responsáveis, a médio e longo prazo, pela baixa capacidade do indivíduo de deliberar sobre suas ações de maneira satisfatória.

Fioravanti, Shayani, Borges \& Balieiro (2005) afirmam que, há certo tempo, vem sendo discutida a importância de uma boa qualidade de vida no ambiente acadêmico. No ambiente acadêmico, os efeitos do estresse são potencializados devido ao ritmo imposto por suas demandas, a saber: exigências ao longo do processo de formação; quantidade excessiva de atividades; extensa lista de leitura; cobranças por rendimentos melhores; entre outras.

Recentemente, reconhece-se que o estresse em ambiente escolar e acadêmico tem sido interesse de investigações com perspectivas diversificadas. Hanzelmann et al. (2020) desenvolveram uma pesquisa com foco no estresse ocupacional de professores do ensino fundamental I. Os autores propuseram uma reflexão sobre a relação entre o ambiente de trabalho e a influência do ambiente na saúde dos indivíduos, revelando que as condições dos professores eram inapropriadas em relação aos aspectos físicos do ambiente. No contexto da educação superior, Preto et al. (2020) apresentam um mapeamento que associa fatores pessoais e ambientais a estresse. O contexto de investigação foi com estudantes do curso de enfermagem. Os resultados da investigação apontaram para o estresse associado a problemas de saúde, uso de medicamentos, reconhecimento do estresse por meio do autorrelato ou percepção e exigências de reajustamento social. Diante disso, o interesse desta investigação surge a partir da necessidade de mapear os efeitos do estresse no contexto da educação superior.

O objetivo deste artigo é mapear as relações entre o estresse e o desempenho acadêmico de alunos da educação superior. Para isso, realizou-se uma pesquisa exploratória 
de natureza qualitativa em que alunos do $1^{\circ}$ e do $5^{\circ}$ semestre do curso superior de Tecnologia em Gestão Ambiental do Instituto Federal de Educação, Ciência e Tecnologia do Rio Grande do Norte, campus Mossoró, responderam a um questionário para identificar suas percepções sobre o estresse acadêmico. Simultaneamente, essas percepções foram relacionadas ao seu desempenho.

Nesse sentido, realizou-se uma pesquisa exploratória no ano de 2017, de natureza qualitativa, em que participaram seis alunos voluntários. Dos seis estudantes voluntários, três cursavam o $1^{\circ}$ semestre e três cursavam o $5^{\circ}$ semestre do curso no turno da manhã. Os participantes assinaram o Termo de Consentimento Livre e Esclarecido (TCLE) e, por questões éticas, sua identificação é preservada, e suas respostas ao questionário são tratadas de maneira seletiva para que possam revelar o objetivo da investigação e ilustrar as possíveis relações entre estresse e desempenho acadêmico.

O artigo está dividido em 4 seções. Além desta introdução, a seção de escolhas teórico-metodológicas apresenta a discussão sobre o impacto do estresse no desempenho de funções cognitivas e descreve o contexto e os procedimentos da investigação. A seção de discussão dos dados comenta as respostas dos alunos ao questionário, relacionando essas respostas ao desempenho acadêmico. Nas considerações finais, são apresentadas sugestões de atitudes ou atividades que possam minimizar o estresse percebido pelos alunos.

\section{Metodologia}

O estresse é uma reação natural do organismo. Essa reação ocorre quando vivenciamos situações de perigo ou ameaça, o que nos coloca em estado de alerta ou alarme, provocando alterações físicas e emocionais. Essa patologia também pode ser definida como um estado de esforço do organismo para adaptar-se a situações que ameaçam a vida e o equilíbrio interno. Esse processo de adaptação provoca várias alterações, como, por exemplo, o aumento da adrenalina. Atualmente, o termo estresse é utilizado tanto para nomear essa resposta do organismo como para referir-se às situações que promovem os efeitos desse estado. Em outras palavras, o estresse é todo acontecimento biológico, psicológico ou social que abala a homeostase do ser humano, necessitando de reação do organismo ao fator estressor (Santos \& Alves Jr, 2007).

Aspectos psicológicos e ambiente externo influenciam diretamente o estresse no ser humano, como a falta de estrutura básica para a manutenção da vida, recursos financeiros deficientes, entre outros, que acabam por interferir em sua qualidade de vida (Rio, 1995). 
Assim, em princípio, o estresse não é uma doença, constituindo-se na percepção do organismo para lidar com as situações que se apresentam, sendo, então, uma resposta do organismo a um determinado estímulo, o qual varia de pessoa para pessoa. Para Lipp (1996, p. 20), "Stress é definido como uma reação do organismo, com componentes físicos e/ou psicológicos, causada pelas alterações psicofisiológicas [...]”. Vale salientar que as situações de estresse apontadas pelo estudo podem fazer parte da rotina da vida acadêmica na modernidade recente, e isso pode afetar o desempenho acadêmico de alunos da educação superior. Em perspectiva restrita, um aluno com bom desempenho acadêmico é aquele que obtém notas positivas em testes que devem ser aplicados ao longo do processo acadêmico. Ou seja, essa perspectiva se relaciona mais fortemente com o que é denominado rendimento. No entanto, o desempenho acadêmico possui definições mais complexas.

Touron (1984) afirma que, em termos educativos, o desempenho é um dos resultados da aprendizagem, suscitado pela atividade educativa do professor e produzido no aluno, ainda que esteja claro que nem toda aprendizagem é produto da ação docente. Em percepção também ampliada, para Jiménez (2000), o desempenho acadêmico é concebido como um construto que não só contempla atitudes e motivação dos alunos, mas também outras variáveis intervenientes, como aspectos docentes, relação professor-aluno, entorno familiar, etc. Levando em consideração tanto as perspectivas restritas quanto as perspectivas mais ampla, é importante destacar que "a avaliação do desenvolvimento e do aprendizado dos alunos, isto é, a determinação de quão bem os alunos alcançam os objetivos acadêmicos, é uma das principais maneiras pelas quais as instituições demonstram suas efetividades" (Braga \& Franco, 2004, p. 1).

Levando em consideração a discussão sobre o impacto do estresse nas funções cognitivas e a compreensão sobre desempenho acadêmico, é possível pressupor que o estresse no contexto acadêmico pode impactar negativamente o desempenho dos alunos, sendo os alunos considerados a razão de existir das instituições de ensino. Nesta investigação, são protagonistas os participantes/alunos do $1^{\circ}$ e do $5^{\circ}$ semestre do curso superior de Tecnologia em Gestão Ambiental do Instituto Federal de Educação, Ciência e Tecnologia do Rio Grande do Norte, campus Mossoró. Essa escolha contextual é fundamentada teoricamente por meio da perspectiva de Gadotti (2007) sobre escola pública. Embora os Institutos Federais sejam considerados Instituições de Ensino Superior, seu ambiente escolar o constitui como um lugar especial, de esperança e luta. É um espaço de interação que reflete sobre as possibilidades de transformação social. Assim, essa instituição tem sido apontada como grande potencial para a oferta de "[...] uma nova qualidade de educação universalizada para toda a população" 
(Ciavatta, 2014, p. 202), que pode contribuir para um futuro de superação da dualidade de classes sociais.

Por considerar esse engajamento educacional, social e político, mapear as relações entre o estresse e o desempenho acadêmico de alunos da educação superior constitui-se um primeiro passo possível e necessário rumo a programas de prevenção que devem ser promovidos nessas instituições e em outras com missões sociais e educacionais. As escolhas teórico-metodológicas desta investigação argumentam a favor de que "São necessárias teorizações que dialoguem com o mundo contemporâneo, com as práticas sociais que as pessoas vivem, como também desenhos de pesquisa que considerem diretamente os interesses daqueles que trabalham, agem etc. no contexto de aplicação [...]" (Moita Lopes, 2006, p. 23).

Nessa perspectiva, tem-se empreendido no mapeamento de práticas educativas e aprendizagens no âmbito da Educação Profissional e Tecnológica (EPT). Especialmente na cidade de Mossoró e por meio do Instituto Federal de Educação, Ciência e Tecnologia do Rio Grande do Norte, campus Mossoró, podem ser citados os mapeamentos dos usos da internet por alunos da Educação de Jovens e Adultos (EJA), bem como os possíveis letramentos digitais de idosos no contexto da EJA (Lima \& Brito, 2015; Lima \& Almeida, 2015), além da análise da oferta, das práticas de ensino e dos documentos norteadores institucionais do ensino de línguas, como os Projetos Pedagógicos de Curso (PPC), entre outros (Silva, Varela, Lima \& Lima, 2015; Guerra \& Lima, 2018; Guerra \& Lima, 2019). Reivindicam-se, portanto, empreendimentos de pesquisa que deem visibilidade às vozes situadas para além dos grandes centros urbanos e capitais brasileiras.

Nesse sentido, realizou-se uma pesquisa no ano de 2017, de cunho exploratório e de campo, em que participaram seis alunos voluntários do curso superior de Tecnologia em Gestão Ambiental do Instituto Federal de Educação, Ciência e Tecnologia do Rio Grande do Norte, campus Mossoró. Dos seis alunos voluntários, três cursavam o $1^{\circ}$ semestre e três cursavam o $5^{\circ}$ semestre do curso no turno da manhã.

Todos os alunos participantes assinaram o Termo de Consentimento Livre e Esclarecido (TCLE) e, por questões éticas, sua identificação é preservada, e suas respostas ao questionário são tratadas de maneira seletiva para que possam revelar o objetivo da investigação e ilustrar as possíveis relações entre estresse e desempenho acadêmico. Tendo como instrumento de coleta de dados um questionário por escrito entregue aos participantes voluntários, reconhece-se a importância de dar visibilidade à voz dos alunos do curso, possibilitando que eles reflitam sobre o estresse acadêmico e seu próprio desempenho. $\mathrm{Na}$ próxima seção, comentam-se as respostas dos alunos ao questionário, relacionando essas 
respostas ao desempenho acadêmico.

\section{Resultados e Discussão}

Quando os seis alunos responderam ao questionário sobre como o estresse pode afetar o desempenho acadêmico, foi possível identificar que todos os alunos concordam que o estresse pode vir a afetar o rendimento. No entanto, algumas respostas sinalizaram para o semestre cursado pelos alunos, isto é, revelou-se que no começo do curso ainda não era possível presenciar tanto o estresse no dia a dia acadêmico. Outras respostas, por outro lado, já descreviam momentos em que o estresse foi vivenciado pelos alunos. O exemplo, a seguir, ilustra, por meio do relato de uma aluna de $5^{\circ}$ semestre, que situações de estresse foram percebidas a partir do $2^{\circ}$ semestre do curso, em virtude de demandas pessoais, familiares e acadêmicas.

Estudante do $5^{\circ}$ semestre "Assim, o estresse acaba com o nosso rendimento escolar, porque, tipo é muita pressão, tipo em relação aos nossos pais, em relação ao conteúdo, aos professores, e se depender da situação que a gente se encontra né? Eu digo pelo momento que eu me encontrei mais estressada durante o curso foi no segundo período que eu pagava oito disciplinas, estudava de manhã, de tarde, e estava grávida. Era assim, eu já sou estressada normalmente, mas esse período foi o pior de todos, porque eu briguei com muitas pessoas. E eu vi que eu não tinha um bom rendimento, tipo, eu estudava para as disciplinas e tudo, mas eu não tinha um bom rendimento, eu não dormia direito e não me alimentava bem".

No relato, é possível relacionar não apenas as causas do estresse, mas também suas consequências. No mapeamento das relações entre o estresse e o desempenho, são identificados conteúdos, professores e quantidade de disciplinas. Vale salientar que o estresse, causado em virtude de demandas pessoais, familiares e acadêmicas, resulta em prejuízo à saúde não apenas mental, mas também física da aluna, que não consegue dormir ou se alimentar satisfatoriamente. Esse relato corrobora a tese de que, no transcurso da vida, em determinadas ocasiões, as pressões biopsicossociais são responsáveis por desequilíbrios na homeostase do indivíduo, prejudicando seu desempenho nas mais variadas circunstâncias, pois a aluna estava, inclusive, em período gestativo. Assim, pressões geradoras de estresse são vivenciadas na vida pessoal, social, profissional e, não menos diferente, durante a trajetória 
acadêmica (Monteiro, Freitas \& Ribeiro, 2007).

O questionário aplicado com os alunos fez com que eles refletissem sobre os fatores que podem causar o estresse no ambiente acadêmico, destacando os mais importantes. Entre as opções, encontravam-se: atividades; prazos; exigências pessoais; notas; relacionamento com professor; bullying.

Estudante do $1^{0}$ semestre "Prazos curtos, porque é uma pressão, como você disse é pressão, tensão e insistência né? Preocupação com notas também, afetando, pois, seu rendimento cai quando você está estressado, você não consegue se concentrar, você não consegue ter o foco na aula. Preocupação com a nota, você fica muito naquele negócio de que tem que tirar nota boa, e tem que se esforçar para isso. Pois se não tirar boas notas, você vai ter que prestar conta a quem você acha que deve, como a sua família. E também as múltiplas atividades, porque fica muita coisa para você fazer”.

No relato, o fator de estresse mais evidente é a preocupação com notas. Essa preocupação está diretamente relacionada à percepção do estado de estresse. Além disso, o fator notas se imbrica com prazos curtos, exigências pessoais - "você vai ter que prestar conta com quem acha que deve, como a sua família" -, e a quantidade de atividades. É importante perceber que o relato se refere a um aluno de $1^{\circ}$ semestre. Levando em consideração essa condição, pode-se levantar a hipótese de que o estresse acadêmico talvez esteja relacionado a uma continuidade do estresse escolar vivenciado por alunos brasileiros na transição de fases muito importantes de suas vidas, isto é, a transição entre o ensino médio (educação secundária) e a educação superior (faculdade/universidade). Nessa situação, a preocupação com o rendimento acadêmico na perspectiva de notas (des)vela que a escola está intimamente ligada à sociedade, conforme a compreensão de escola de Gadotti (2007), reproduzindo, neste caso, possivelmente, um agente promotor da competitividade e do sucesso que pode ser medido em números. É possível notar, ainda, o agravamento dessa percepção com o relato do aluno do $5^{\circ}$ semestre.

Estudante do $5^{\circ}$ semestre "Eu acredito que as exigências externas e pessoais, porque como falei a cobrança ela é muito grande pelos nossos pais, por nós mesmas, na verdade, a gente se cobra muito, as vezes nem é tão necessário isso tudo. A preocupação com notas, porque é tipo como se a gente fosse a nossa nota né? A gente tira uma nota baixa só que não é exatamente isso. A gente não é a nota que a gente 
Research, Society and Development, v. 9, n. 8, e637984240, 2020

(CC BY 4.0) | ISSN 2525-3409 | DOI: http://dx.doi.org/10.33448/rsd-v9i8.6240

tira, a gente é muito mais que isso. Tem gente que tira nota baixa só que se saiu muito bem na aula, na interação, e tem gente que tira nota alta, por exemplo, colando, né? Então, essa preocupação com nota também é tensa. Tem também as múltiplas atividades, porque quando a gente inventa de fazer muita coisa, a gente não consegue dar $100 \%$ em todas as atividades, a gente sempre escolhe uma e o resto vai só levando com a barriga".

Pelo relato, verifica-se que a relação entre o estresse e o desempenho acadêmico é fortemente estabelecido por meio do rendimento compreendido como a preocupação com notas. Além disso, embora a relação predominante entre estresse e desempenho acadêmico seja estabelecida por meio do fator notas, esse fator encontra-se imbricado a outros fatores "exigências externas e pessoais" -. Salienta-se que um fator gerador de estresse pode ser percebido de maneira diferente por duas pessoas, demonstrando que as reações aos estímulos estressores são individuais e subjetivas, o que reflete a capacidade adaptativa de cada indivíduo. Observa-se ainda, uma cultura de categorização, essencialização e ranqueamento desses sujeitos, quando o participante relata que a nota e ele são a mesma coisa - "é tipo como se a gente fosse a nossa nota" -. No entanto, em relação a isso, vale ressaltar que a missão social do Instituto Federal pode ter impactado a percepção do aluno do $5^{\circ}$ semestre quanto as suas práticas acadêmicas e à importância de se compreender como um sujeito integral, já que o mesmo reivindica um status para além de uma simples nota - “A gente não é a nota que a gente tira, a gente é muito mais que isso" - Essa problematização é muito cara a um projeto de educação que vise à superação da dualidade de classes, conforme apontado por Ciavatta (2014). Por meio de suas respostas ao questionário, os alunos também revelaram o quanto o estresse pode impactar na sua aprendizagem. Esse impacto varia significativamente, tendo sido possível flagrar seu ápice na relação entre aspectos psicofisiológicos.

Estudante do $5^{\circ}$ semestre "[...] quanto mais estressada, menos eu absorvo as coisas, porque eu não consigo. Se eu estou estressada, eu fico logo com dor de cabeça, porque eu sinto muita dor de cabeça, por conta da falta de sono, eu durmo mal, fico logo com dor de cabeça e eu não consigo absorver nada, de jeito nenhum".

Pelo relato, fica evidente que o estresse se relaciona dialeticamente com a aprendizagem. A narrativa da aluna do $5^{\circ}$ semestre ilustra o impacto provocado pelo estresse 
em seu desempenho acadêmico tendo em vista aspectos da saúde mental que, no caso em especial, provoca consequências físicas desagradáveis - "sinto muita dor de cabeça" -. Esse reconhecimento de sintomas em si pode ser associado à compreensão de que a dificuldade de aprendizagem pode aparecer em qualquer fase da vida, podendo ocorrer em qualquer indivíduo saudável, sem qualquer tipo de problema físico. No caso em especial, o estresse pode desencadear uma série de problemas que envolvem, inclusive, o físico da aluna, afinal, quando ela confronta as situações estressoras, são desencadeadas consequências psicofisiológicas - "eu fico logo com dor de cabeça, porque eu sinto muita dor de cabeça, por conta da falta de sono" -, conforme discutido por Lipp (1996).

Tendo em vista os relatos dos alunos, comprova-se que os estudantes no período acadêmico podem desencadear o estresse, pois a vida universitária exige vivências de mudanças e adaptações, as quais podem precipitar o aparecimento de estresse, gerando, muitas vezes, dificuldades de aprendizagem e alterações no desempenho acadêmico.

$\mathrm{O}$ estresse pode ocorrer durante as várias fases da vida, contudo, a entrada para o ensino superior pode levar muitos estudantes ao estresse devido às inúmeras mudanças e adaptações exigidas por esse novo ambiente. Baseando-se nisto, nota-se que a sala de aula pode vir a ser um ambiente propicio a produzir fatores estressantes tanto para o educador como para o educando. É necessário que se saiba identificar quais são esses fatores e em que medida eles podem prejudicar o comportamento, as emoções, a aprendizagem e o trabalho de quem participa deste ambiente.

Por fim, a análise dos dados revelou que o estresse está mais relacionado à pressão por notas satisfatórias e é mais evidente entre os alunos do $5^{\circ}$ semestre, podendo levar à conclusão preliminar de que o estresse é percebido ao longo da vida acadêmica e influencia o desempenho acadêmico em semestres mais avançados. Além disso, esse tipo de investigação fortalece a criação de inteligibilidades sobre o estresse no contexto escolar e acadêmico, conforme tem sido demonstrado nas pesquisas recentes de Hanzelmann et al., 2020 e Preto et al., 2020. Nessa direção, Almeida (2002) menciona que o processo de aprendizagem do aluno deve ser ativo. A aprendizagem deve ocorrer por meio de métodos que promovam a iniciativa e a responsabilidade do aluno para sua própria aprendizagem. As estratégias de aprendizagem podem instrumentalizar o aluno a diversificar suas formas de estudo, promover atitudes de autoavaliação e reflexão sobre seu desempenho acadêmico. Essas são apenas breves sugestões de atitudes ou atividades que podem minimizar o estresse percebido pelos alunos. Tendo como instrumento de coleta de dados um questionário entregue por escrito aos participantes voluntários, alunos matriculados no curso superior de Tecnologia em Gestão Ambiental, 
reconhece-se a importância de dar visibilidade à voz dos alunos do curso, possibilitando que eles reflitam sobre o estresse acadêmico e seu próprio desempenho, bem como sensibilizar professores, técnico-administrativos e gestores para a construção de práticas que reduzam as tensões geradoras de estresse.

\section{Considerações Finais}

A realização desta investigação exploratória, de natureza qualitativa, objetivou mapear as relações entre o estresse e o desempenho acadêmico de alunos da educação superior. Ao considerar o curso superior de Tecnologia em Gestão Ambiental do Instituto Federal de Educação, Ciência e Tecnologia do Rio Grande do Norte, campus Mossoró, a investigação traz contribuições para a comunidade acadêmica local, pois foi possível dar visibilidade a situações, experiências e práticas que podem provocar estresse nos estudantes e comprometer seu desempenho.

Considera-se que o objetivo da investigação tenha sido alcançado, pois foi possível trazer aqueles que vivem as práticas sociais, neste caso, estudantes da educação superior, para opinar sobre o fenômeno/problema de estresse, identificando essa questão como pertinente aos seus interesses e produzindo sentido de acordo com seu ponto de vista.

$\mathrm{O}$ estresse pode ocorrer durante as várias fases da vida, contudo, a entrada para o ensino superior pode levar muitos estudantes ao estresse devido às inúmeras mudanças e adaptações exigidas por esse novo ambiente. Baseando-se nisto, nota-se que a sala de aula pode vir a ser um ambiente propicio a produzir fatores estressantes tanto para o educador como para o educando. É necessário que se saiba identificar quais são esses fatores e em que medida eles podem prejudicar o comportamento, as emoções, a aprendizagem e o trabalho de quem participa deste ambiente. A análise dos dados revelou que o estresse está mais relacionado à pressão por notas satisfatórias e é mais evidente entre os alunos do $5^{\circ}$ semestre, podendo levar à conclusão preliminar de que o estresse é percebido ao longo da vida acadêmica e influencia o desempenho acadêmico em semestres mais avançados.

A análise empreendida nesta investigação possibilita a afirmação de que o estresse é vivenciado pelos alunos no ambiente acadêmico, e que isso pode vir a se intensificar à medida que seu curso avança. Dessa forma, reivindica-se que mapear as relações entre o estresse e o desempenho acadêmico de alunos da educação superior constitui-se um primeiro passo possível rumo a programas de prevenção e combate à nocividade do estresse nas experiências escolares que devem transformar vidas. Os dados resultantes da aplicação de um questionário 
com alunos do $1^{\circ}$ e do $5^{\circ}$ semestre do curso superior de Tecnologia em Gestão Ambiental do Instituto Federal de Educação, Ciência e Tecnologia do Rio Grande do Norte, campus Mossoró, demonstraram as percepções sobre as condições do contexto acadêmico e pessoal associadas à presença de estresse, de modo a oferecer subsídios para práticas de intervenção, o que pode ser objeto de continuidade de pesquisa.

Por fim, é necessário refletir sobre a possibilidade de continuidade da pesquisa sobre o estresse acadêmico. Sugerem-se pesquisas que fortaleçam o diálogo com o setor pedagógico e de apoio acadêmico, por exemplo, o de assistência estudantil (serviço social, psicologia), para o estabelecimento de mapeamentos mais complexos e com uma maior fonte de dados.

\section{Referências}

Almeida, L. S. (2002). Facilitar a aprendizagem: ajudar os alunos a aprender e a pensar. Psicologia Escolar e Educacional, 6(2), 155-65.

Braga, D. B. \& Franco, L. R. H. (2004). R. Revolucionando as técnicas de aprendizagem da engenharia com o EAD. World Congress on Engineering and Technology Education, São Paulo: [s.n.], 1083-87.

Ciavatta, M. (2014). O ensino integrado, a politecnia e a educação omnilateral: por que lutamos?. Trabalho \& Educação, 23(1), 187-205. Acesso em 01 julho 2020, em https://periodicos.ufmg.br/index.php/trabedu/article/view/9303

Fioravanti, A. R., Shayani, D. A., Borges, R. C., \& Balieiro, R. C. (2005). Estudo sobre os fatores de stress entre alunos da Unicamp. Revista Ciências do Ambiente On-Line, Campinas, $1(1), 41-48$.

Gadotti, M. (2007). A escola e o professor: Paulo Freire e a paixão de ensinar.1 ed. São Paulo, Publisher Brasil.

Guerra, W. T., \& Lima, S. C. (2018). Inglês para fins específicos em Cursos Superiores de Tecnologia na Educação Profissional. Linguagens \& Cidadania, 20, 1-11. Acesso em 01 de julho de 2020, em https://periodicos.ufsm.br/LeC/article/view/\%2A\%2A 
Guerra, W. T., \& Lima, S. C. (2019). An ESP Teaching Proposal for Oil and Gas Vocational Courses. International Journal of Language \& Linguistics, 6(4), 87-93, 2019. Acesso em 01 de julho de 2020, em https://doi.org/10.30845/ij1l.v6n4p10

Hanzelmann, R. S., et al. (2020). Estresse do professor do Ensino Fundamental: o ambiente em evidência. Research, Society and Development, 9(8), e53982910, 2020. Acesso em 05 de julho de 2020, em http://dx.doi.org/10.33448/rsd-v9i8.2910

Jiménez, M. (2000). Competencia social: intervención preventiva en la escuela. Infancia y sociedad, Universidad de Alicante, [S.1.], 24, 21-48.

Lima, S. C., \& Almeida, L. V. O. S. (2015). Letramento digital de idoso no contexto da EJA em Mossoró-RN. Tear: Revista de Educação, Ciência e Tecnologia, 4(1), 1-14. Acesso em 01 de julho de 2020, em https://doi.org/10.35819/tear.v4.n1.a1902

Lima, S. C., \& Brito, T. S. O. (2015). Usos da internet por alunos do PROEJA do IFRN Mossoró. Artefactum (rio de janeiro), 11(2), 31. Acesso em 01 de julho de 2020, em http://artefactum.rafrom.com.br/index.php/artefactum/article/view/829

Lipp, M. E. N. (1996). Pesquisas sobre stress no Brasil: saúde, ocupações e grupos de risco. Campinas: Papirus.

Moita Lopes, L. P. (2006). Uma linguística aplicada mestiça e ideológica: interrogando o campo como linguista aplicado. In: Moita Lopes, L. P. (Org.). Por uma linguística aplicada INdisciplinar. São Paulo: Parábola Editorial, 13-42.

Monteiro, C. F. S., Freitas, J. F. M., \& Ribeiro, A. A. P. (2007). Estresse no cotidiano acadêmico: o olhar dos alunos de enfermagem da Universidade Federal do Piauí. Piauí.

Preto, V. A., et al. (2020). Associação entre fatores pessoais e ambientais com o estresse recente em estudantes de enfermagem. Research, Society and Development, 9(6), e113962572. Acesso em 05 de julho de 2020, em http://dx.doi.org/10.33448/rsd-v9i6.2572

Rio, R. P. (1995). O fascínio do stress. Del Rey, Belo Horizonte, 11-59. 
Santos, A. F., \& Alves Jr, A. (2007). Estresse e estratégias de enfrentamento em mestrandos de ciências da saúde. Psicologia: Reflexão e crítica, 20 (1), 104-13.

Silva, G. M., Varela, A. N. D. C., Lima, M. T., \& Lima, S. C. (2015). Núcleo de Línguas do IFRN Campus Mossoró NUPEL/MO. Revista Diálogos da Extensão, 1(1), 55-58. Acesso em 01 de julho de 2020, em https://doi.org/10.15628/dialogos.2015.3905

Touron, J. (1984). Factores del rendimiento académico en la Universidad. Pamplona: EUNSA.

\section{Porcentagem de contribuição de cada autor no manuscrito}

Charliany Silva Araújo - 50\%

Leonor de Araújo Bezerra Oliveira - 30\%

Samuel de Carvalho Lima - 20\% 